\title{
The Use of Corticosteroids in the Management of Herpes Zoster
}

\author{
Lori L. MacFarlane, PharmD, BCPS, Melissa M. Simmons, PbarmD, \\ and Melissa H. Hunter, MD
}

Editors' Note: This month we continue the new featureSTEPped Care: An Evidence-Based Approacb to Drug Therapy. These articles are designed to provide concise answers to the drug therapy questions that family physicians encounter in their daily practice. The format of the feature will follow the mnemonic STEP: safety (an analysis of adverse effects that patients and providers care about), tolerability (pooled dropout rates from large clinical trials), effectiveness (how well the drugs work and in what patient population[s]), and price (costs of drug, but also cost-effectiveness of therapy). ${ }^{1}$ Hence, the name STEPped Care.

Since the informatics pioneers at McMaster University introduced evidence-based medicine, ${ }^{2}$ Slawson and Shaughnessy ${ }^{3,4}$ bave brought it to mainstream family medicine education and practice. This feature is designed to furtber the mission of searching for the trutb in medical practice. Autbors will provide information in a structured format that allows the readers to get to the meat of a therapeutic issue in a way that can belp physicians (and patients) make informed decisions. The articles will discourage the use of disease-oriented evidence to make treatment decisions. Examples of diseaseoriented evidence include blood pressure lowering, decreases in bemoglobin $A_{1 c}$, and so on. We will include studies that provide POEMs-patient-oriented evidence that matters (myocardial infarctions, pain, strokes, mortality, etc) -with the goal of offering patients the most practical, appropriate, and scientifically substantiated therapies. Whenever possible, number needed to treat to observe benefit in a single patient will also be included as a way of defining advantages in terms that are relatively easy to understand. 5,6

At times this effort will be frustrating. Even as vast as the biomedical literature is, it does not always support what clinicians do. We will avoid making conclusions that are not supported by POEMs. Nevertbeless, POEMs should be incorporated into clinical practice. The rest is up to the reader. Blending POEMs with rational thought, clinical experience, and importantly, patient preferences can be the essence of the art of medicine.

We bope you will find these articles useful and easy to read. Your comments and suggestions are welcome. You may contact the editors through the editorial office of $7 A B F P$ or on the Internet (bttp://limic.isu.edu/drugsteps/intro.btml). We bope the articles provide you with useful information that can be applied in everyday practice, and we look forward to your feedback.

Rex W. Force, PharmD, STEPped Care Feature Editor John Geyman, MD, Editor Fournal of the American Board of Family Practice

\section{References}

1. Shaughnessy AF, Slawson DC, Bennett JH. Separating the wheat from the chaff: identifying fallacies in pharmaceutical promotion.J Gen Intern Med 1994;9:563-8.

2. Evidence-based medicine: a new approach to teaching the practice of medicine. Evidence-Based Medicine Working Group. JAMA 1992;268:2420-5.

3. Slawson DC, Shaughnessy AF, Bennett JH. Becoming a medical information master: feeling good about not knowing everything.J Fam Pract 1994;38:505-13.

4. Shaughnessy AF, Slawson DC, Bennett JH. Becoming an information master: a guidebook to the medical information jungle. J Fam Pract 1994;39:489-99.

5. Laupacis A, Sackett DL, Roberts RS. An assessment of clinically useful measures of the consequences of treatment. $N$ Engl J Med 1988;318:1728-33.

6. Wiffen PJ, Moore RA. Demonstrating effectiveness-the concept of numbers-needed-to-treat. J Clin Pharm Ther 1996;21:23-7.
The diagnosis of acute herpes zoster often introduces the issue of treatment with antiviral agents, with or without corticosteroids. Although there is evidence to support the use of antiviral agents (acy-

Submitted, revised, 10 March 1998.

From the Department of Family Medicine (LLM, MHH)), and the Department of Pharmacy Practice (MMS), Medical University of South Carolina, Charleston. Address reprint requests to Lori L. MacFarlane, Pharm D, Department of Family Medicine, Medical University of South Carolina, 171 Ashley Ave, Charleston, SC 29425. clovir, famciclovir, valacyclovir) to reduce the duration of acute zoster pain and postherpetic neuralgia, the use of corticosteroids is not as clearly defined. ${ }^{1,2}$ While the acute phase of herpes zoster is somewhat bothersome, the occurrence of postherpetic neuralgia can be debilitating.

Herpes zoster is an acute vesicular eruption involving one or two adjacent dermatomes, with pain often preceding the eruption by days to weeks. ${ }^{1} \mathrm{It}$ is caused by the reactivation of latent virus dormant in sensory nerves from a previous episode of 
primary varicella. Epidemiologic data indicate the annual incidence of cases of herpes zoster ranges from 0.4-1.6/1000 in immunocompetent persons younger than 20 years to $4.5-11.0 / 1000$ in those older than 80 years. Acute zoster pain usually resolves spontaneously, but in some cases the pain persists for months to years. Postherpetic neuralgia is generally pain that persists 1 month or longer after the vesicular rash has cleared. Overall, postherpetic neuralgia occurs in 9 to 14 percent of patients with herpes zoster. As age increases, however, the risk and duration of postherpetic neuralgia also rises. ${ }^{3}$ Treatment of postherpetic neuralgia is difficult, and the complexity of the underlying changes account for the lack of efficacy of a single therapeutic approach. Physicians continue to search for an effective means to prevent postherpetic neuralgia.

\section{Methods}

We searched MEDLINE from January 1966 through November 1997 using the search terms "herpes zoster," "neuralgia," "glucocorticoids," "synthetic," "prednisone," and "adrenal cortex hormones." The search was limited to human clinical trials published in English language journals. Studies were selected if they evaluated patient-oriented evidence that matters (POEMs), such as the duration of acute zoster pain and postherpetic neuralgia or quality of life, as primary outcomes. The number needed to treat to prevent one negative outcome, when possible, was calculated. In this review we examine the use of corticosteroids in the treatment of herpes zoster and the prevention of postherpetic neuralgia using the STEP approach: safety (an analysis of adverse effects that patients and providers care about), tolerability (pooled dropout rates from clinical trials), effectiveness (how well do corticosteroids work and in what patient population [s]), and price (costs of drug, and also cost effectiveness of therapy, if available).

\section{Safety}

The major safety issue regarding the use of corticosteroids in herpes zoster is the risk of viral dissemination in the presence of corticosteroid-induced immunosuppression. Although this concern is largely theoretical, Merselis and colleagues ${ }^{4}$ described a series of case reports in 1964 in which 17 of 175 patients developed disseminated herpes zoster. Five of the 17 patients were receiving corticosteroids or adrenocorticotropin hormone (ACTH). Eleven patients also had a serious underlying illness, such as Hodgkin disease or leukemia. Because there were other predisposing factors in addition to corticosteroid use in this case series, it is impossible to establish a causative relation.

Randomized clinical trials have not shown an increase in viral dissemination in any patients treated with corticosteroids when compared with a control group..$^{5-11}$ The only trial in which dissemination was reported included 201 patients randomized to receive combinations of acyclovir, prednisone, and placebo. ${ }^{11}$ One patient in the acyclovir-placebo group and two patients in the prednisone-placebo group developed cutaneous dissemination, all of which resolved without further complications. Most studies, however, excluded patients with underlying immunosuppression or hematologic malignancies. ${ }^{5-11}$ It appears, therefore, that corticosteroids do not markedly enhance the risk of viral dissemination in patients who have herpes zoster and no underlying immunosuppression.

\section{Tolerability}

Reactions to corticosteroids range from mild gastrointestinal effects to profound suppression of the hypothalamic-pituitary axis. In general, shortterm corticosteroid therapy does not result in persistent metabolic effects or long-term complications. Short-term dosing is not free of adverse effects, however.

A trend toward an increase in blood pressure and total body weight was found in patients who took ACTH or prednisone for a period of 3 weeks, ${ }^{7}$ although exact values were not reported. Acute cardiac insufficiency was reported in 1 patient receiving prednisone therapy in a study involving 78 patients, but blood glucose and blood pressure were not evaluated in an attempt to assure blinding. ${ }^{8}$

Patients taking prednisolone combined with acyclovir for 7 to 21 days were found to have a higher incidence of side effects when compared with those taking acyclovir alone, but dropout rates were similar among groups (10-14 percent). ${ }^{10}$ Nineteen percent reported at least one adverse event in the combination group compared with 13 percent in the acyclovir-only group. Dyspepsia, edema, and hot flushes occurred more frequently 
Table 1. Clinical Trial Outcomes Comparing Prednisolone Versus Placebo in Herpes Zoster.

\begin{tabular}{llcr}
\hline Dependent Variable & Outcome Measure & Hazard Ratio (95\% CI) & $P$ Value \\
\hline Progression of rash & Last day with new lesions & $0.985(0.79-1.23)$ & 0.89 \\
& First day with no new vesicles & $0.860(0.69-1.07)$ & 0.18 \\
& First day with full crusting & $0.856(0.68-1.07)$ & 0.17 \\
& First day with 100\% healing & $0.924(0.75-1.14)$ & 0.40 \\
Change from baseline in & At day 7 & Data not provided & $<0.01$ \\
pain-intensity score & At day 14 & Data not provided & $<0.01$ \\
& At day 21 & Data not provided & 0.96 \\
Cessation of pain & Median day to first cessation & $0.876(0.69-1.11)$ & 0.27 \\
& Median day to complete cessation & $1.043(0.81-1.34)$ & 0.74 \\
\hline
\end{tabular}

Adapted from Wood et al. ${ }^{10}$

in patients taking corticosteroids, but the difference was not statistically significant. Laboratory abnormalities, including changes in granulocytes, hemoglobin, neutrophils, platelets, and urea nitrogen, occurred with greater frequency in the group taking corticosteroids; each abnormality returned to normal after tapering the prednisolone. One patient taking prednisolone developed hematemesis several weeks after discontinuation, and the authors concluded this condition could have been related to corticosteroid use.

The Collaborative Antiviral Study Group found no significant difference in the number of adverse events reported or in dropout rates (13-19 percent) in patients treated with combinations of acyclovir, prednisone, and placebo. ${ }^{11}$ In all four groups, the most frequently reported events were gastrointestinal, especially nausea and vomiting. Hyperglycemia (blood glucose greater than 180 $\mathrm{mg} / \mathrm{dL}$ ) developed in 7 patients, 5 of whom were receiving prednisone.

The remaining clinical trials reported no adverse effects associated with corticosteroid therapy. ${ }^{5-9}$ Psychiatric effects of corticosteroids were not reported in any clinical trial. ${ }^{5-11}$ Most trials excluded patients with underlying disease states, such as renal insufficiency, hypertension, osteoporosis, diabetes mellitus, and peptic ulcer disease. As a result, patients who were more likely to experience adverse side effects to corticosteroids did not participate.

\section{Efficacy}

Historically, physicians have prescribed corticosteroids to patients with herpes zoster in hopes of preventing postherpetic neuralgia. This practice was based on small, poorly controlled clinical tri- als. ${ }^{5,6,12-15}$ More recently, the use of antiviral agents in the treatment of herpes zoster has resulted in reductions of early zoster pain and residual pain at 6 months. ${ }^{2}$ The use of corticosteroids has remained controversial, however, as small, controlled trials failed to confirm their perceived benefit. ${ }^{7-9}$

Recently two large, randomized, double-blind, placebo-controlled trials evaluated the benefit of combining corticosteroids and acyclovir in the management of herpes zoster. ${ }^{10,11}$ Immunocompetent patients were included if they had a clinical diagnosis of herpes zoster and a rash for 72 hours or less. In general, exclusion criteria were pregnancy, women of childbearing potential not protected by contraception, renal insufficiency, hypertension, insulin-dependent diabetes, peptic ulcer disease, osteoporosis, severe psoriasis, hypersensitivity to acyclovir, and patients taking barbiturates, anticonvulsant drugs, systemic corticosteroids, rifampin, or other antiviral drugs.

Wood and colleagues ${ }^{10}$ studied 349 patients, mean age 59 years, with an average duration of rash between 49 and 55 hours (Table 1). Patients were randomly assigned to one of four treatment groups: 7 days of oral acyclovir therapy $(800 \mathrm{mg}$ five times a day) and placebo, 7 days of acyclovir therapy and 21 days of oral prednisolone $(40 \mathrm{mg} / \mathrm{d}$ days $0-6,30 \mathrm{mg} / \mathrm{d}$ days $7-10,20 \mathrm{mg} / \mathrm{d}$ days $11-14$, $10 \mathrm{mg} / \mathrm{d}$ days $15-18,5 \mathrm{mg} / \mathrm{d}$ days 19-21), 21 days of acyclovir therapy and placebo, or 21 days of acyclovir therapy and 21 days of prednisolone. $\mathrm{Pa}$ tients were frequently examined to assess the progression of the rash and intensity of pain during the acute phase ( 21 days), then monthly for 6 months. Patients kept a pain and sleep diary, which was reviewed by an investigator to provide a weekly assessment of pain. 
Table 2. Clinical Trial Outcomes Comparing Prednisone Versus Placebo in Herpes Zoster.

\begin{tabular}{llll}
\hline Dependent Variable & Outcome Measure & Risk Ratio (95\% CD) & $P$ Value \\
\hline Cutaneous healing at l month & Time to total crusting & $1.25(0.9-1.74)$ & NS \\
& Time to total healing & $1.11(0.78-1.59)$ & NS \\
Quality of life at 1 month & Time to cessation of acute neuritis & $2.28(1.35-3.86)$ & $<0.05$ \\
& Time to uninterrupted sleep & $1.65(1.14-2.41)$ & $<0.05$ \\
& Time to return to 100\% usual activity & $1.74(1.21-2.51)$ & $<0.05$ \\
Six-month evaluation of pain & Time to no use of analgesic agents & $2.25(1.42-3.54)$ & $<0.05$ \\
\hline
\end{tabular}

Adapted from Whitely et al. ${ }^{11}$

NS - not significant.

No significant differences in acute rash progression or percentage of rash healed at days 7, 14, or 21 were detected. With respect to acute zoster pain (to day 21), the changes from baseline in pain intensity scores were comparable in all groups; however, patients treated with corticosteroids had a greater reduction in pain on days 7 and 14. There were no significant differences detected between any of the four treatment groups in the incidence or severity of postherpetic neuralgia at 6 months. The number needed to treat could not be calculated from the data provided. The authors concluded that corticosteroids conferred only limited initial benefit but had no appreciable influence on the incidence or severity of postherpetic neuralgia.

The Collaborative Antiviral Study Group studied 201 patients, median age 61 years, 76 percent of whom had a duration of rash of less than 2 days (Table 2). ${ }^{11}$ Patients were randomly assigned to one of four treatment groups: acyclovir $(800 \mathrm{mg} 5$ times a day) and prednisone ( $60 \mathrm{mg} / \mathrm{d}$ days $1-7,30$ $\mathrm{mg} / \mathrm{d}$ days $8-14$, and $15 \mathrm{mg} / \mathrm{d}$ days $15-21$ ), acyclovir and prednisone placebo, prednisone and acyclovir placebo, or two placebos. Participants were examined daily until their skin had completely healed, and then monthly for a total of 6 months.

In patients taking acyclovir, cutaneous healing was significantly better at 1 month and resulted in a more rapid return to the patients' usual daily activities. Corticosteroids offered no significant benefit with respect to cutaneous healing, but the quality-of-life evaluation found that corticosteroids offered a significant benefit at 1 month. Improvements in quality of life in combination (acyclovir and prednisone) and placebo groups, respectively, included time to cessation of acute neuritis (specific data not provided), time to uninterrupted sleep ( 5 versus 26 days), time to return to normal activity ( 3 versus 21 days), and time to no use of analgesic agents (14 versus 28 days). ${ }^{16}$ Neither acyclovir nor prednisone led to earlier resolution of postherpetic neuralgia. The number needed to treat could not be calculated from the data provided. The authors concluded that combination therapy improved quality of life in patients older than 50 years of age with acute herpes zoster, although this study again confirmed that the addition of corticosteroids had no effect on the course of postherpetic neuralgia.

\section{Price}

The cost of 21 days of corticosteroids is minor when compared with the cost of antiviral agents. Regardless of the tapering schedule, prednisone costs less than $\$ 10$. No cost-effectiveness analyses have evaluated corticosteroids in the treatment of herpes zoster and the prevention of postherpetic neuralgia.

\section{Summary}

Although corticosteroids have been evaluated in the management of herpes zoster since the $1950 \mathrm{~s}$, their role has not been well established until the publication of recent clinical trials. Corticosteroids in combination with acyclovir can reduce acute zoster pain and improve short-term (1 month) quality of life in patients older than 50 years. $\mathrm{Nu}$ merous patients were excluded from clinical trials, however, because of concomitant chronic conditions, including renal insufficiency, hypertension, insulin-dependent diabetes, peptic ulcer disease, and osteoporosis. Because this patient mix is commonly encountered in primary care, is this information useful to family physicians?

Practically speaking, short courses of corticosteroids are commonly prescribed for other acute conditions, with appropriate monitoring for corti- 
Table 3. Drug STEPS Quick Read: Use of Corticosteroids in the Management of Herpes Zoster

\begin{tabular}{ll}
\hline Safety & $\begin{array}{l}\text { Theoretical risk of viral dissemination in } \\
\text { corticosteroid-treated patients not supported in } \\
\text { small clinical trials involving immuno- } \\
\text { competent patients }\end{array}$ \\
Tolerability & $\begin{array}{l}\text { Nausea, vomiting, dyspepsia, edema, and hot } \\
\text { fushes reported more frequently (not signifi- } \\
\text { cant) in corticosteroid-treated patients. Pooled } \\
\text { dropout rate approximately } 14 \%\end{array}$ \\
Effectiveness & $\begin{array}{l}\text { Corticosteroids can reduce acute zoster pain } \\
\text { and improve short-term (1 month) quality of } \\
\text { life, but have no effect on the development or } \\
\text { severity of postherpetic neuralgia }\end{array}$ \\
Price & $\begin{array}{l}\text { A21-day prednisone taper costs < } \$ 10 . \\
\text { No cost-effectiveness studies are available } \\
\text { Corticosteroid use is reasonable in patients }\end{array}$ \\
older than 50 years with herpes zoster and well- \\
controlled chronic conditions, if appropriate \\
monitoring is undertaken
\end{tabular}

costeroid-related adverse effects. Similarly, corticosteroid use is reasonable for patients with herpes zoster and well-controlled chronic conditions, if appropriate monitoring is undertaken. If corticosteroids are to be added to an antiviral agent, both should be initiated within 72 hours of the onset of the herpes zoster rash. Corticosteroids, however, have no appreciable effect on the incidence or duration of postherpetic neuralgia (Table 3).

\section{References}

1. Kost RG, Straus SE. Postherpetic neuralgiapathogenesis, treatment, and prevention. $\mathrm{N}$ Engl J Med 1996;335:32-42.

2. Jackson JL, Gibbons R, Meyer G, Inouye L. The effect of treating herpes zoster with oral acyclovir in preventing postherpetic neuralgia. A meta-analysis. Arch Intern Med 1997;157:909-12.

3. Watson PN, Evans RJ. Postherpetic neuralgia. A review. Arch Neurol 1986;43:836-40.
4. Merselis JG, Kaye D, Hook EW. Disseminated herpes zoster: a report of 17 cases. Arch Intern Med 1964;113:679-86.

5. Eaglstein WH, Katz R, Brown JA. The effects of early corticosteroid therapy on the skin eruption and pain of herpes zoster. JAMA 1970;211:1681-3.

6. Keczkes K, Basheer AM. Do corticosteroids prevent post-herpetic neuralgia? Br J Dermatol 1980;102: 551-5.

7. Clemmensen OJ, Andersen KE. ACTH versus prednisone and placebo in herpes zoster treatment. Clin Exp Dermatol 1984;9:557-63.

8. Esmann V, Geil JP, Kroon S, Fogh H, Peterslund NA, Petersen CS, et al. Prednisolone does not prevent post-herpetic neuralgia. Lancet 1987;2:126-9

9. Benoldi D, Mirizzi S, Zucchi A, Allegra F. Prevention of post-herpetic neuralgia. Evaluation of treatment with oral prednisone, oral acyclovir, and radiotherapy. Int J Dermatol 1991;30:288-90.

10. Wood MJ, Johnson RW, McKendrick MW, Taylor J, Mandal BK, Crooks J. A randomized trial of acyclovir for 7 days or 21 days with and without prednisolone for treatment of acute herpes zoster. $\mathrm{N}$ Engl J Med 1994;330:896-900.

11. Whitely RJ, Weiss $H$, Gnann JW Jr, Trying S, Mertz GJ, Pappas PG, et al. Acyclovir with and without prednisone for the treatment of herpes zoster: a randomized, placebo-controlled trial. The National Institute of Allergy Infectious Diseases Collaborative Antiviral Study Group. Ann Intern Med 1996;125:376-83.

12. Gefland $M$. Treatment of herpes zoster with cortisone. JAMA 1954;154:911-2.

13. Appleman DH. Treatment of herpes zoster with ACTH. N Engl J Med 1955;253:693-5.

14. Sauer GC. Herpes zoster: treatment of post-herpetic neuralgia with cortisone, corticotropic, and placebos. Arch Dermatol 1955;711:488-91.

15. Elliot FA. Treatment of herpes zoster with high doses of prednisone. Lancet 1964;2:610-1.

16. Whitley R, Gnann JW, Weiss H. Acyclovir plus steroids for herpes zoster. Ann Intern Med 1997; 126:832. 